\title{
Levantamento histórico e relatos de inundações do córrego do Gregório na região central do município de São Carlos - SP
}

\author{
Historical survey and reports of flooding of the Gregório stream at the central region of São Carlos \\ municipality
}

Ana Cristina Bagatini Marotti, ana_marotti@hotmail.com Karoline Eduarda Lima Santos, karol.eduarda21@gmail.com Leonardo Gallo Macera, leonardo.macera@hotmail.com Luiza de Lima Neves, luiza.Ineves@gmail.com Juliano Costa Gonçalves, juliano@ufscar.br

Érica Pugliesi, epugliesi@ufscar.br

\begin{abstract}
Resumo: As inundações frequentes no município de São Carlos têm acarretado diversos danos aos munícipes, sejam eles materiais ou imateriais. O presente trabalho objetivou identificar esses danos a fim de documentar o efeito dessa problemática na vida de comerciantes e moradores da região e analisar quais têm sido as ações dos órgãos públicos nesse âmbito. O histórico levantado mostrou-nos que as enchentes nunca cessaram, mas que de tempos em tempos algumas mais marcantes são as que mais trazem malefícios à população. A pesquisa realizada com os órgãos competentes mostrou que a maioria das obras realizadas são de correção e que, portanto, não resolvem o problema. Pela experiência que possuem, conclui-se que tais órgãos poderiam implantar mais medidas voltadas à prevenção de tais problemas, sendo possível, assim, encontrar uma solução realmente eficaz.
\end{abstract}

Palavras-chave: Inundações; Danos Materiais e Imateriais; Planejamento urbano.

\begin{abstract}
The frequent flooding at São Carlos municipality has caused several damages to residents, material or immaterial. This study intended to identify these damages in order to document the effect of this problem on the merchants' life and area residents, and analyze what has been done by the public organs about this. The history showed up that floods never ceased, but that time to time some of the most remarkable are those that bring more harms to the population. The research made with competent agencies showed that most of the works are corrective measures and therefore does not solve the problem. By the experience they have, it is concluded that such agencies could implement more measures aimed to the prevention of such problems, being possible to find a truly effective solution.
\end{abstract}

Keywords: Floods; Material and Immaterial Damage; Urban Planning.

$\mathrm{O}$ crescimento das cidades ocorrido nas últimas décadas transformou o Brasil em um país essencialmente urbano (83\% de população urbana) (TUCCI, 2008). Grande parte desse crescimento deu-se, e ainda se dá, de forma desordenada e sem planejamento, em que parte da população acaba ocupando áreas ambientalmente frágeis e com topografia inapropriada para construir (áreas de encosta e de inundação de corpos hídricos, por exemplo).
Nesse contexto, destacamos as inundações, que representam o transbordamento das águas de um curso d'água, atingindo a planície de inundação ou área de várzea (DEFESA CIVIL DE SÃO BERNARDO DO CAMPO, 2013). Vinculadas a um processo natural de cheia dos corpos hídricos, essas áreas de inundação deveriam ser evitadas durante o processo de uso e ocupação do solo; entretanto, devido a processos sociais relacionados com a dinâmica do mercado 
de terras (como segregação social e falta de terra urbanizada a preços acessíveis) e com a ausência de planejamento urbano (GONÇALVES, 2010), a ocupação de áreas inundáveis torna-se a regra, não a exceção. Assim, os problemas gerados por uma inundação dependem fundamentalmente da forma e grau de ocupação das áreas ribeirinhas e da frequência de ocorrência das cheias (MMA et al, 2004).

As inundações por vezes são consideradas desastres naturais, mas, para tanto, se faz necessário conhecer um pouco mais os modelos e definições por trás desse conceito. Gilbert (1998) elenca três paradigmas que, para ele, agrupam o conceito de desastre: o desastre como um agente externo ameaçador; o desastre como expressão social da vulnerabilidade; e, por fim, o desastre como um estado de incertezas geradas pelas próprias instituições. O segundo e o terceiro paradigmas nortearão a análise no decorrer deste trabalho. Gilbert (1998) ressalta, no segundo paradigma, que os desastres são processos sociais com uma realidade historicamente construída que as vulnerabilidades revelam, e, no terceiro paradigma, que os desastres nas sociedades complexas seriam criados pelas frágeis articulações entre as especialidades científicas que não permitem uma orientação mais abrangente da rotina da vida social gerando desorientação na sociedade pela ausência e, também, pelo excesso de informação e comunicação. Outro autor que norteia a análise é Beck (2010, p. 23, grifo do autor), que afirma que a "produção social de riqueza é acompanhada sistematicamente pela produção social de riscos". O fundamento dos riscos está na "transformação de ameaças civilizacionais à natureza em ameaças sociais, econômicas e políticas sistêmicas que representa o real desafio do presente e do futuro, o que justifica o conceito de sociedade de risco" (BECK, 2010, p. 99). Por conta disso é que os problemas ambientais são antes de tudo problemas sociais advindos de uma determinada visão de mundo e de uma relação com a natureza (BECK, 2010). Quando, nesta relação do homem com a natureza, uma ameaça hidrometeorológica (como a chuva, por exemplo) encontra - se realiza sobre - uma vulnerabilidade socioambiental (uma determinada exposição à ameaça derivada de aspectos sociais e ambientais como a ocupação de áreas próximas aos corpos hídricos) temos um desastre. Assim, o desastre significa a disrupção da vida social (VALENCIO, 2009) e está ligado a uma conjuntura de processos sociais, ambientais e tecnológicos.

A Sub-bacia do córrego do Gregório, situada no Município de São Carlos - SP, é uma região caracterizada pela frequente ocorrência de inundações. Nessa sub-bacia, os processos sociais, ambientais e tecnológicos podem ser observados no contexto das inundações, as quais, ao atingirem diretamente a população que ali reside ou trabalha, se constituem em desastre que afeta a vida social do município, pois se trata de uma região central com predominância comercial.

Devido aos enormes prejuízos e danos causados por esses eventos, foi instituída a Política Nacional de Proteção e Defesa Civil - PNPDEC por meio da LEI No 12.608, DE 10 DE ABRIL DE 2012. Na PNPDEC, são abrangidas ações de prevenção, mitigação, preparação, resposta e recuperação voltadas à proteção e defesa civil, devendo integrar-se às várias outras políticas a fim de se garantir a promoção do desenvolvimento sustentável. Ou seja, trata-se de uma Política que visa não só a ações pós-impacto, mas também preventivas, de forma que se evitem os danos causados à população civil.

O presente artigo tem por objetivo descrever e analisar os danos materiais e imateriais das inundações na região central da Bacia do Córrego do Gregório e seus impactos materiais e imateriais ${ }^{1}$ sobre a população local. Este artigo está dividido em duas seções com suas respectivas subseções para além desta introdução e da conclusão. A próxima seção versa sobre os procedimentos metodológicos adotados no trabalho.

\section{Metodologia}

A realização da presente pesquisa deu-se por meio de 3 (três) etapas: 1. delimitação e caracterização da área de estudo; 2.coleta de informações relacionadas ao histórico de inundações ocorridas no município durante o período de 2007-2013; e 3. aplicação de questionários abertos para a identificação dos danos materiais e imateriais sofridos pelos residentes do percurso da região central do Córrego do Gregório.

\section{Etapa 1 - Delimitação e caracterização da área de estudo.}

A Bacia do Córrego do Gregório está localizada no município de São Carlos e possui área total de 15,6 km² (Figura 1). Seu clima é o Tropical de Altitude, com verões chuvosos e invernos secos, com seis meses quentes e úmidos e seis meses frios e secos. A temperatura diária máxima anual é de $26,9^{\circ} \mathrm{C}$ e a mínima anual de $16,2^{\circ} \mathrm{C}$. A precipitação pluvial média anual é aproximadamente 1500 mm (RIGHETTO, 2005). Seu principal corpo hídrico, o córrego do Gregório, tem uma extensão de aproximadamente $7 \mathrm{~km}$ (SALVADOR et al, 2013), percorre a área urbana no sentido leste - oeste,

\footnotetext{
1 Os bens culturais imateriais estão relacionados aos saberes, às habilidades, às
} crenças, às práticas, ao modo de ser das pessoas (PORTAL BRASIL, 2009). 
atravessa a região central e deságua no Rio Monjolinho, na rotatória em frente ao shopping center, conhecida como "Rotatória do Cristo". Com relação aos corpos hídricos que compõem a bacia, nota-se que os afluentes do córrego do Gregório só estão presentes em um dos lados. Os outros afluentes foram suprimidos pela ação antrópica, ou estão totalmente canalizados, de forma que não constam nas cartas topográficas. É o caso do Córrego do Simeão, que se une ao Gregório na região central, que também influencia os eventos de enchentes (Figura 2).

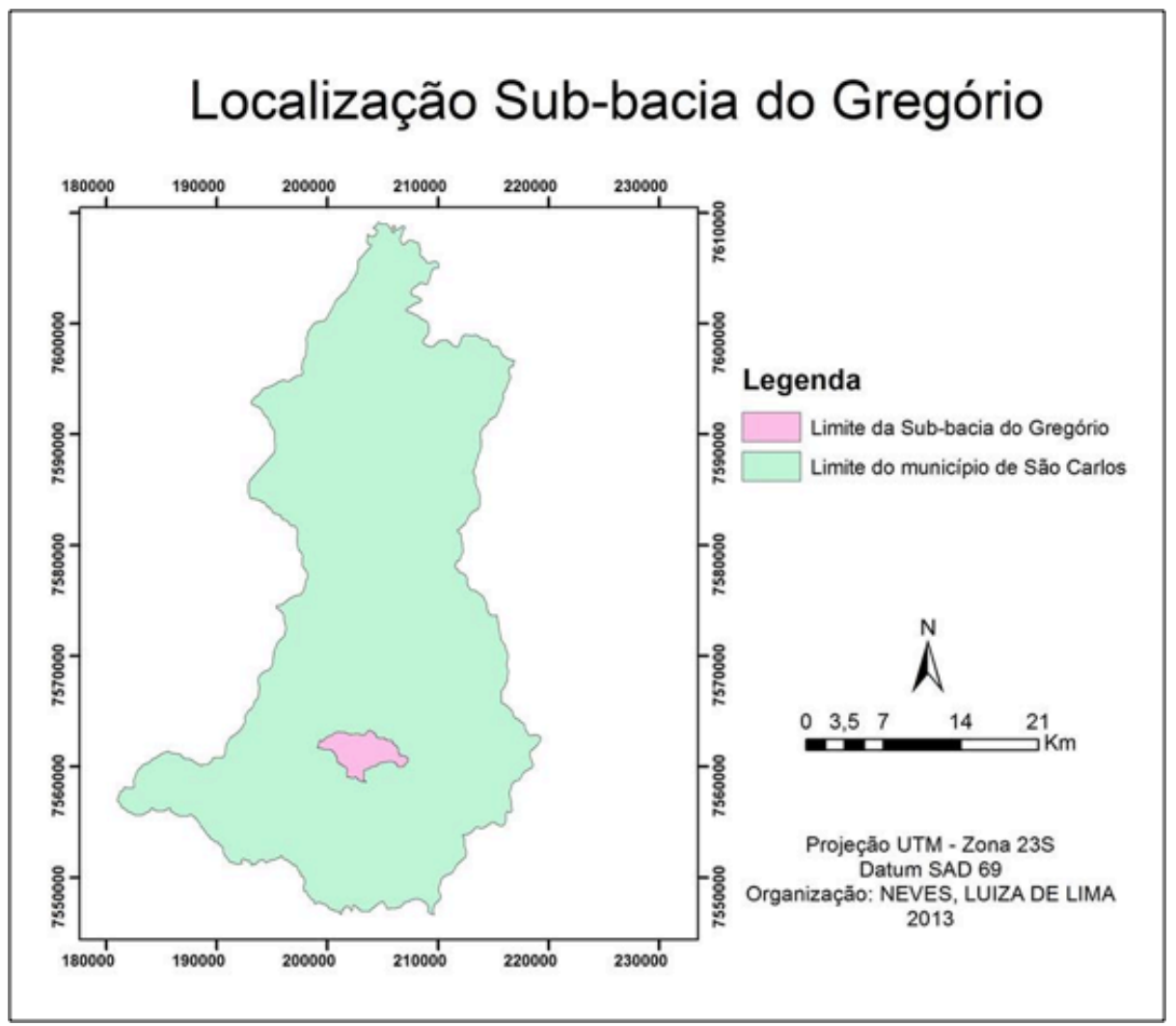

Figura 1: Localização da Sub-Bacia do Córrego do Gregório em São Carlos/SP

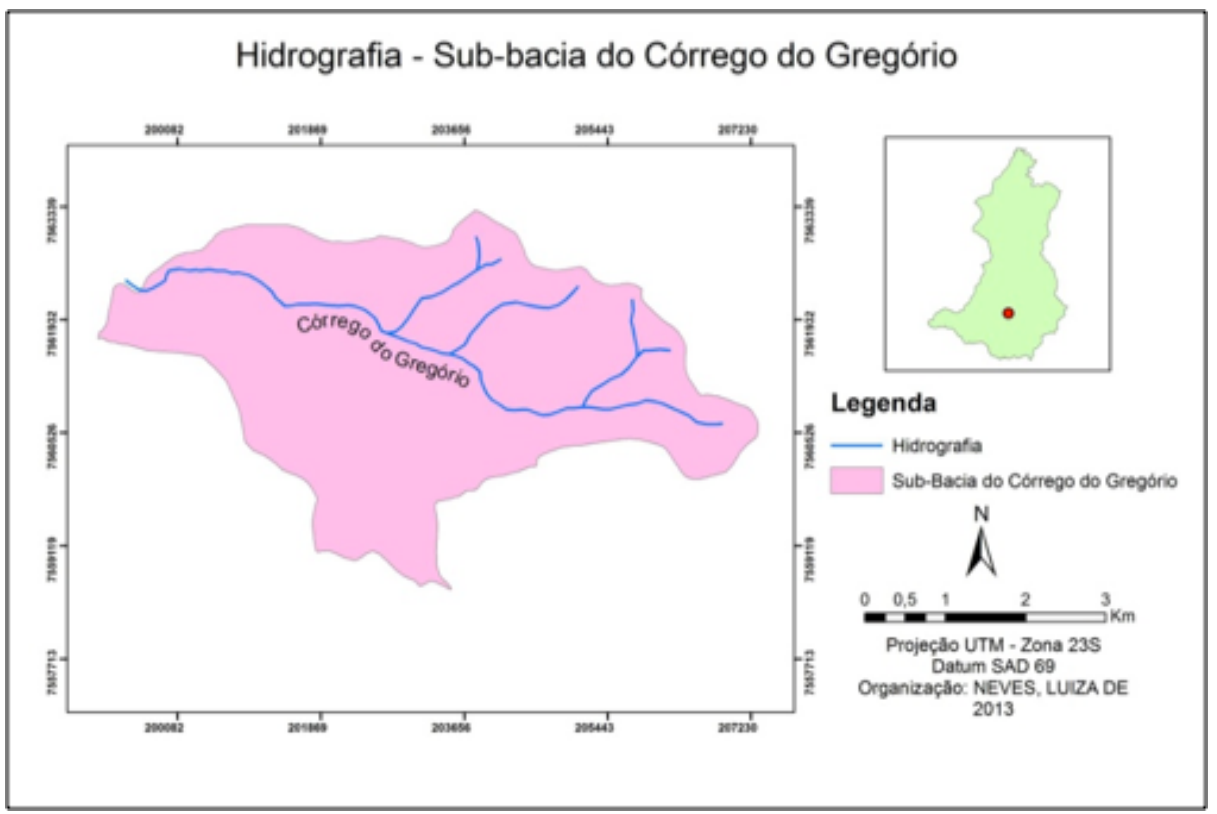

Figura 2: Hidrografia da Sub-bacia do Córrego do Gregório em São Carlos/SP 
Quanto ao seu aspecto de relevo, consultando bibliografias disponíveis, nota-se que o terreno não apresenta variações muito acentuadas, o que propicia a ocupação dessa área. Segundo Biasi (1992), as classes de declividades $<5 \%$ referem-se ao limite utilizado internacionalmente para uso urbano-industrial e em trabalhos de planejamento urbano; 5-12\% definem o limite máximo do emprego da mecanização na agricultura; e as de 12-30\% compreendem o limite máximo de acordo com a legislação - Lei 6766/79 - que o define como o limite máximo para urbanização sem restrições. Para efeito didático, foram desconsideradas as duas demais classes citadas pelo autor, visto que a maior taxa de declividade encontrada na área de estudo foi de $22 \%$ (Figura 3).

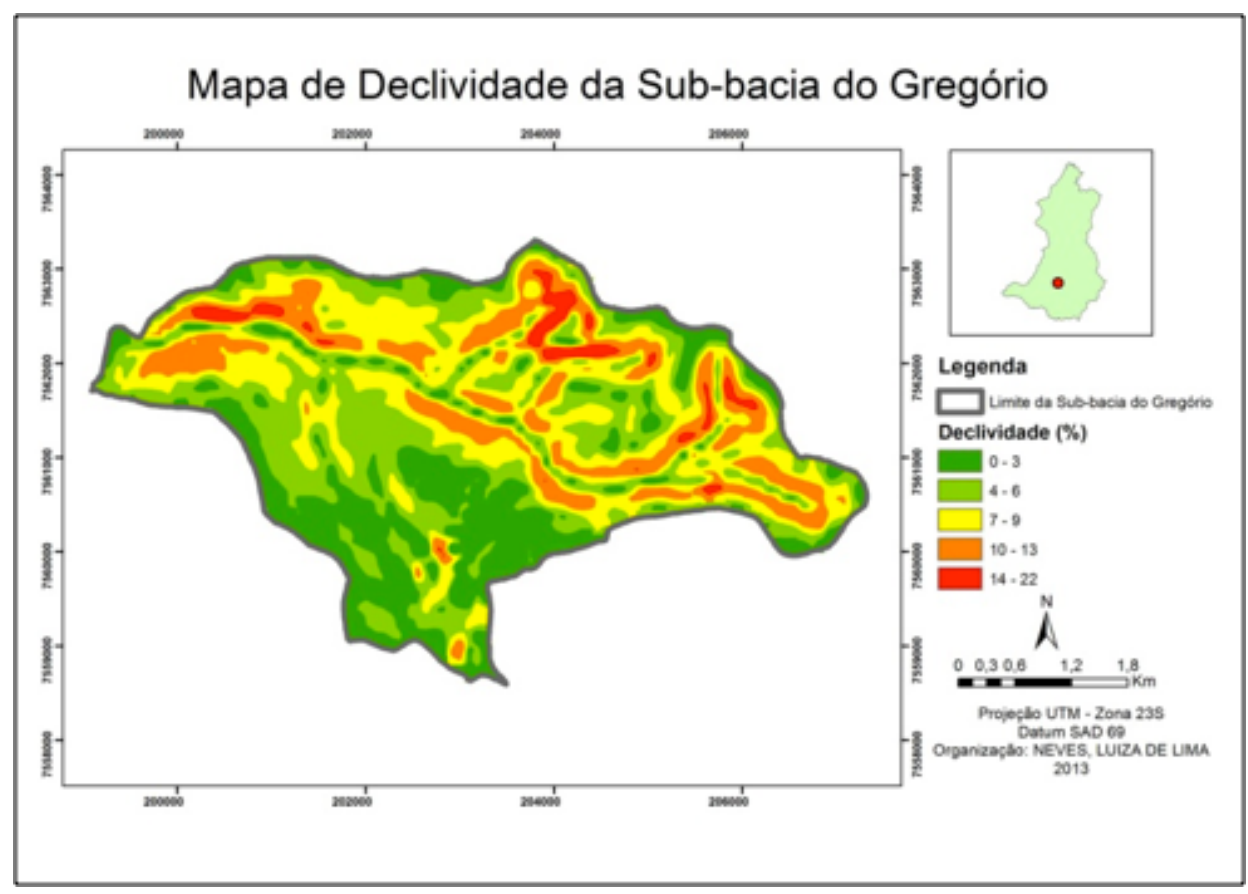

Figura 3: Declividade da Sub-bacia do Córrego do Gregório em São Carlos/SP

Por possuir uma área bastante extensa, fez-se necessário delimitar uma área que seria analisada para a viabilização do projeto. Assim, optou-se por trabalhar com uma das principais áreas afetadas na região, a Av. Comendador Alfredo
Maffei, no trecho que se estende entre a Rua Dom Pedro II e a Rua 9 de Julho, por 515 metros de comprimento, como pode ser observado na figura 4 , abaixo.

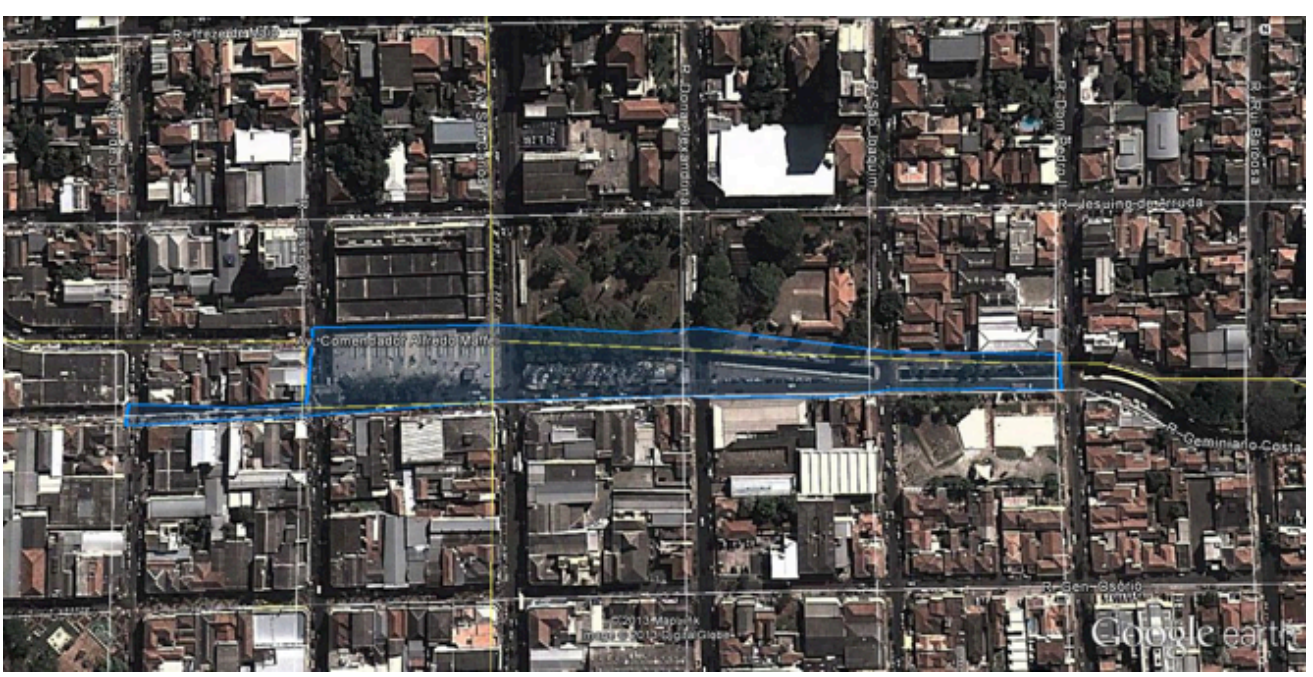

Figura 4: Localização da área de estudo em trecho do Córrego do Gregório em São Carlos/SP 
Etapa 2 - Coleta de informações relacionadas ao histórico de inundações ocorridas no município durante o período de 2007-2013.

Quanto ao apanhado de informações, recorreu-se aos registros presentes na Defesa Civil de São Carlos e aos artigos relacionados. Complementarmente, foi consultada a mídia local, com o objetivo de buscar notícias registradas nesse período referente às inundações.

Etapa 3 - Aplicação de questionários abertos para a identificação dos danos materiais e imateriais sofridos pelos residentes do percurso da região central do Córrego do Gregório.

Para a identificação dos impactos negativos resultantes (materiais e imateriais), houve a aplicação de entrevistas baseadas em um roteiro específico para cada público que seria entrevistado: Defesa Civil Municipal, Comerciantes próximos ao Córrego do Gregório e Poder Público Municipal, os quais estão presentes no apêndice desta pesquisa. Foram contabilizadas 15 (quinze) entrevistas.

As perguntas feitas aos comerciantes visaram identificar as experiências vivenciadas com inundações na área selecionada pelo trabalho. Foram abordados temas, tais como: prejuízos já obtidos (tanto materiais quanto imateriais), hipótese de sair do local devido às situações desfavoráveis e formas de adaptação às circunstâncias. Para a Defesa Civil o intuito era conhecer as reais medidas de prevenção, preparação e resposta perante as ocorrências de inundação, especificadamente na região do mercado. Quanto ao Poder Público, o objetivo era conhecer as medidas estruturais que foram realizadas, as que estariam por vir, e se havia conhecimento sobre as demandas/os anseios populacionais.

Foram feitas duas perguntas em comum para todos os entrevistados, visando comparar suas opiniões com relação a que medidas poderiam ser tomadas para minimizar ou até solucionar a problemática das inundações. Outra pergunta era sobre o hiato temporal de acontecimento de grandes inundações que, recentemente, retornaram; qual seria, na interpretação dos entrevistados, a razão disso.

Em relação ao Poder Público Municipal foram entrevistadas as seguintes pessoas: o Chefe de Divisão de Projetos da Secretaria Municipal de Obras Públicas, Fernando Couto Rosa Almeida, e o Arquiteto da Secretaria Municipal de Habitação e Desenvolvimento Urbano, Rogério A. Almeida. Quanto a Defesa Civil foi entrevistado o Diretor de Segurança Pública e Defesa Civil de São Carlos, Pedro Caballero. No que diz respeito às entrevistas com os comerciantes, foram selecionados 12 (doze) pontos no entorno da área de estudo na qual o efeito das inundações foi considerado mais significativo. Os nomes reais dos entrevistados e dos estabelecimentos comerciais não foram colocados para preservar suas identidades, sendo escolhidos, portanto, nomes fictícios.

Na figura 5 estão representados os doze pontos visitados, sendo que: Ponto 1 - Toninho Calçados; Ponto 2 Loja de calçados; Ponto 3 - Loja do ramo de cosméticos; Ponto 4 - Banca de Jornais; Ponto 5 - Floricultura (Mercado Municipal); Ponto 6 - Loja de móveis e eletrodomésticos; Ponto 7, 8, 9, 10 e 11 - Comércio popular e; Ponto 12 Loja de móveis e eletrodomésticos.

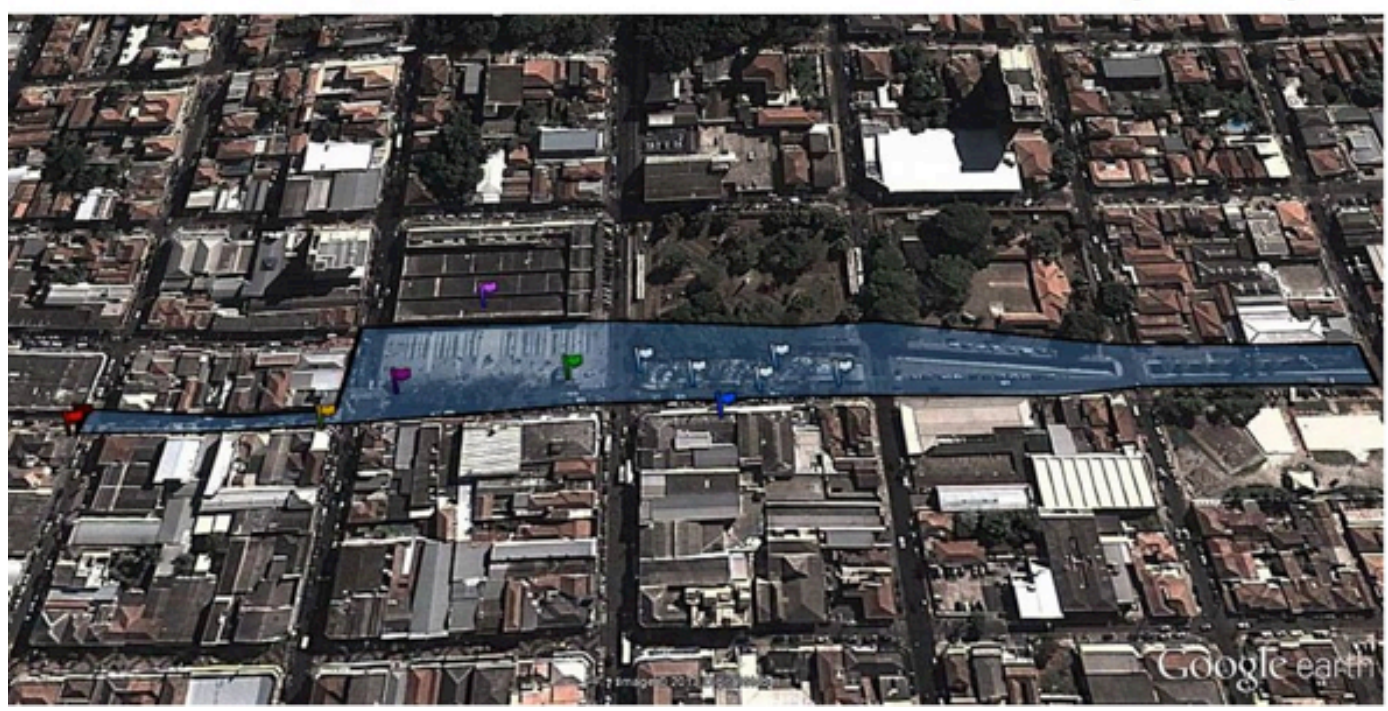

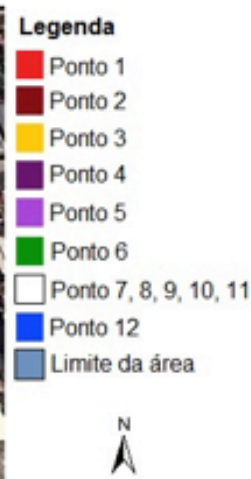

Organizaçăo: MAROTTI, A. C. B SANTOS, K.E. L; MACERA, L. G.; NEVES, L. L. 2013

Figura 5: Localização dos pontos de entrevista na área de pesquisa no Córrego do Gregório em São Carlos/SP 


\section{AS INUNDAÇÕES NO CÓRREGO DO GREGÓRIO: ASPECTOS HISTÓRICOS E DANOS MATERIAIS E IMATERIAIS}

O Córrego do Gregório, desde a fundação do município, sofreu intervenções humanas que, associadas à crescente urbanização e à impermeabilização da microbacia, acarretaram e ainda acarretam várias enchentes na região central da cidade, no entorno do Mercado Municipal. Esta seção discute a história das inundações no Córrego do Gregório, na primeira subseção, e também os danos a que são submetidos os comerciantes da região central do município de São Carlos, na segunda subseção.

\section{Histórico de Inundações}

A história de São Carlos iniciou-se em 1831 com a demarcação da Sesmaria do Pinhal. Contudo, só em 4 de novembro de 1857 é que foi fundado o município, cuja população era composta por algumas pequenas casas ao redor da capela. Hoje, a Matriz da cidade localiza-se a cerca de 2 quarteirões acima do córrego do Gregório (PMSC, s/d).

A cidade atualmente conta com um órgão que atua em ações preventivas, de socorro, assistenciais e reconstrutivas destinadas a evitar ou minimizar desastres, sejam estes de causa natural ou não, como, por exemplo, as enchentes. É a chamada Defesa Civil, criada em 2005 por meio da Lei Municipal 13.557 (PMSC, s/d).

A Defesa Civil possui arquivos sistematizados desde 1992 e registros que datam desde o ano de 1905. A época em que ela mais atua, sendo acionada mais frequentemente, é no período do verão ou na época mais intensa de chuvas, englobando os meses de dezembro a abril, aproximadamente (BORGES, 2006)

Segundo Borges (2006), o primeiro registro de inundação do Córrego do Gregório na área da região central do município data do ano de 1905, o ano em que se começa a registrar esse tipo de evento, ou seja, mesmo antes desse ano é possível que se tenha tido outros casos de enchentes no local.

Em 1974, foi realizada a construção de avenidas marginais ao córrego que contou com a adaptação da hidrografia ao sistema de mobilidade urbana, fazendo com que de maneira geral o córrego sofresse várias intervenções e retificação de seus meandros. A intensa ocupação adjacente ocorreu no período de 1950 a 1970. Contudo, já em 1940 as margens já apresentavam considerável ocupação (MENDES; MENDIONDO, 2007).

De acordo com um levantamento histórico realizado por
Mendes e Mendiondo (2007) sobre registros de inundações ou alagamentos na área no período de 1940 a 2004, os anos de 1947, 1953, 1955, 1957, 1960, 1965, 1968, 1970, 1972, 1973, 1974, 1976, 1977, 1978, 1981, 1987, 1988, 1989, 1990, 1996, 2002, 2003 e 2004 apresentaram esses eventos. Ou seja, em um período de 64 anos, em 23 deles alagamentos foram registrados, sendo que em alguns desses, foram observados mais de um alagamento, mostrando que a área é bem suscetível de enchentes e que esse é um problema antigo que, mesmo com todos os projetos de contenção e minimização das enchentes, persiste. O recorte de jornal (Figura 6), abaixo, e uma foto (Figura 7) retratam eventos de inundação naquela época.

\section{CHUVA DILUVIANA O Gregorio transformado $\mathrm{em}$ mar - Espectaculo inedito e pavoroso - Grandes prejuizos \\ Hontem, das 19 ás 21 ho-/ra do tanque existente na an- ras, desabou sobre a cidade tiga chacara José Bento. A fortissima carga de chuva. Em agua teria, no impeto, arras.}

Figura 6: Inundação na Bacia do Gregório, em 1932 (MENDES E MENDIONDO, 2007).

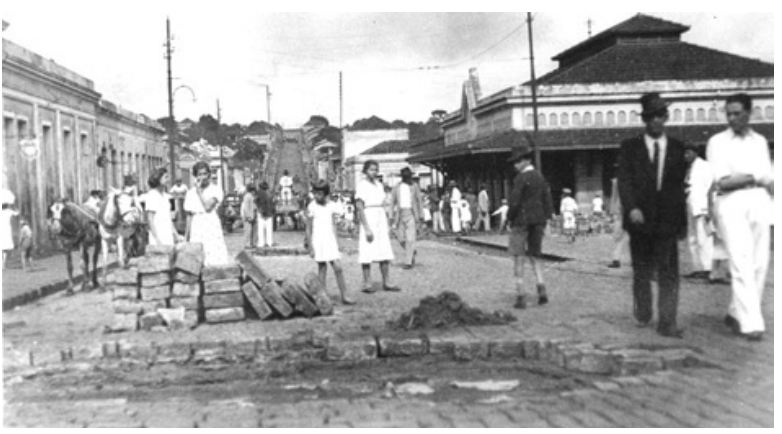

Figura 7: Pavimento de paralelepípedo da Rua Geminiano Costa destruído por inundação em 1940 (Fonte: FotoArte in MENDES E MENDIONDO, 2007).

O levantamento do histórico das inundações ocorridas no período de 2007 - 2013 foi realizado, em sua maior parte, de pesquisas em portais eletrônicos, uma vez que os dados oferecidos pela Defesa Civil estavam incompletos e muitas vezes indisponíveis para consulta.

Para tanto, as principais fontes utilizadas foram o portal de notícias São Carlos Agora e algumas matérias cedidas pela emissora local de televisão (retransmissora da Rede Globo de Televisão) EPTV.

A partir da busca no site São Carlos Agora, foram encontradas 14 (catorze) publicações noticiando as inundações 
na região do Mercado Municipal no período mencionado (2007 - 2013).

Foi então contabilizado um total de 3 (três) eventos de enchentes no ano de 2013, apenas 1 (um) em 2011, 2 (dois) no ano de 2010 e somente 1 (um) em 2008 e 2007, cada.

Abaixo, exemplificaram-se duas notícias, uma datada do ano de 2007 (Figura 8) e outra de 2013 (Figura 9):
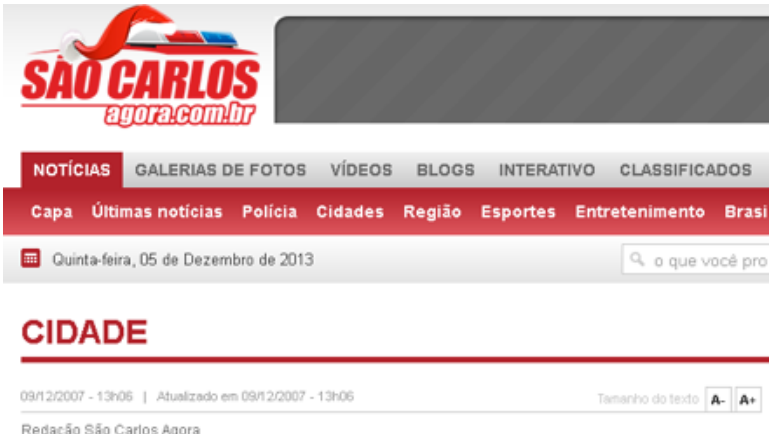

\section{Forte chuva provoca caos na baixada do mercado}

Figura 8: Manchete do portal São Carlos Agora (09/12/2007).

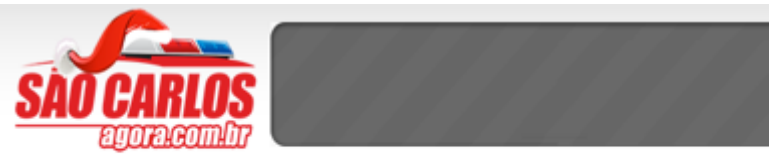

NOTICLAS GALERIAS DEFOTOS VÍDEOS BLOGS INTERATIVO CLASSIFICADOS Capa Últimas noticias Policia Cidades Regiăo Esportes Entretenimento Brasi

Quinta-feira, 05 de Dezembro de 2013 Q. que voof pro

\section{CIDADE}

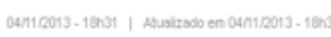

Redaçằo Sāo Carlos Agora

\section{São Carlos volta a registrar alagamentos por causa da chuva}

Friocomendar $\{35 \mid$ Y Tweet $\{2$

A cidade de Şo Carlos voltou a registar alagamentos com a chuva que começou anda pela manhẩ desta segunda-tera (4)

Figura 9: Manchete do portal São Carlos Agora (04/11/2013).

É importante ressaltar que a conceituação de desastre presente nas figuras 6,8 e 9 coloca a ameaça externa, as chuvas, como o elemento causador do desastre. Sendo assim, aspectos como planejamento urbano, impermeabilização urbana, ocupação de áreas de várzea, segregação urbana e o mercado de terras não seriam alvo de qualquer análise, visto que não causam desastres. No entanto, a recorrência do desastre, como pode ser visto na descrição da frequência dos eventos de inundação, não permite alegar desconhecimento e despreparo frente a uma chuva maior que a média do período. O desastre passa a ser estrutural, e não conjuntural, e revela que o local está vulnerável à espera da ameaça (as chuvas) que se encontram no território para iniciar um desastre.

Já os episódios de inundações e/ou alagamentos que atingiram a região de estudo e que foram transmitidos pela emissora de TV, EPTV, contabilizam, aproximadamente, 9 (nove) grandes eventos durante o período abordado (2007-2013).

Um dos acontecimentos que vale destaque foi o ocorrido em 08 de dezembro de 2007, em que as inundações que antes eram constantes voltaram a preocupar os comerciantes da região, como podemos notar com o depoimento de uma vendedora local:

\begin{abstract}
"É preocupante porque começa a chover à noite; você fica com medo. Você vem pra cá (loja), mas independentemente de você vir ou não, não tem como você salvar a mercadoria, se vier de uma vez. Toda vez que chove nós temos esse terror" (Reportagem EPTV).
\end{abstract}

No ano de 2010, no mês de março, choveu cerca de 32 mm em 7 horas; mesmo sendo uma quantia considerada normal de precipitação, foi suficiente para elevar em níveis consideráveis o Córrego do Gregório, deixando os comerciantes em alerta, e causando danos em certos pontos da cidade. Temos também o que aconteceu em 05 de abril do mesmo ano, dia em que, em certas lojas, o prejuízo foi de, no mínimo, $\mathrm{R} \$ 15.000$ (quinze mil reais).

Mesmo não causando danos materiais, as inundações ocorridas no mês de fevereiro de 2011 causaram transtornos aos comerciantes da região da baixada do Mercado Municipal, levando alguns funcionários a modificarem seu horário de trabalho. Chegavam mais cedo ao local de serviço para poder limpar os estragos provocados pelas inundações, e mesmo assim atrasavam o atendimento ao público. Soma-se a tudo isso o desgaste emocional que envolve os comerciantes da região, como podemos notar por meio da fala de uma responsável por uma loja do ramo de calçados:

\footnotetext{
"Quando começou aquela chuva de vento a gente ficou atento. Começou a subir, subir, quando nós vimos que a marginal (...), ia vir mesmo a água, nós já sabíamos que o rio já tinha enchido. Ai nós subimos até aquela soleira e esperamos a chuva passar. Fazia 1 (um) ano que nós não tínhamos enchentes" (Reportagem EPTV).
}

E por fim, um dos últimos grandes eventos que causou grandes prejuízos e pegou os comerciantes da região do Mercado Municipal de surpresa foi o de 22 de outubro de 2013. A força da água arrancou os muros de proteção do 
Córrego do Gregório na altura da Rua Dom Pedro com a Avenida Comendador Alfredo Maffei; um carro que estava no pátio de uma revendedora foi arrastado pra dentro do córrego, por cerca de $3 \mathrm{~km}$, além de outros danos que foram registrados através de câmeras de celular por comerciantes da região, como motos sendo levadas pela correnteza. Temos também os danos causados às lojas da redondeza; uma do ramo de cosméticos precisou se desfazer de grandes quantias de mercadorias que foram prejudicadas e invalidadas devido à inundação. O prejuízo foi de cerca de $R \$ 50.000$ (cinquenta mil reais).

Mesmo tendo esses episódios como parte da rotina do seu local de trabalho, muitos vendedores do comércio popular se assustaram com a grandeza dessa última inundação, como podemos perceber com a declaração de uma das comerciantes:

"Sempre o rio encheu quando não era fechado ali (referente ao trecho localizado à frente do Mercado Municipal), mas nunca entrou água aqui dentro né; isso daqui alagava mas não entrava água. Dessa vez, chegou pra cima do joeIho." Maria, vendedora do comercio popular.

\section{Relatos dos danos materiais e imateriais e vivências de inundações}

O Brasil perde anualmente um valor possivelmente maior que US\$ 1 bilhão em decorrência das enchentes urbanas (BRASIL, 2001).

As enchentes, se comparadas com outras catástrofes naturais, ocupam posição de destaque quanto às perdas em termos econômicos e de fatalidades (Figura 11) (RIGHETTO, 2005), além de serem uma das que ocorrem com mais frequência no mundo, só perdendo para as tormentas como mostra a figura 10 .

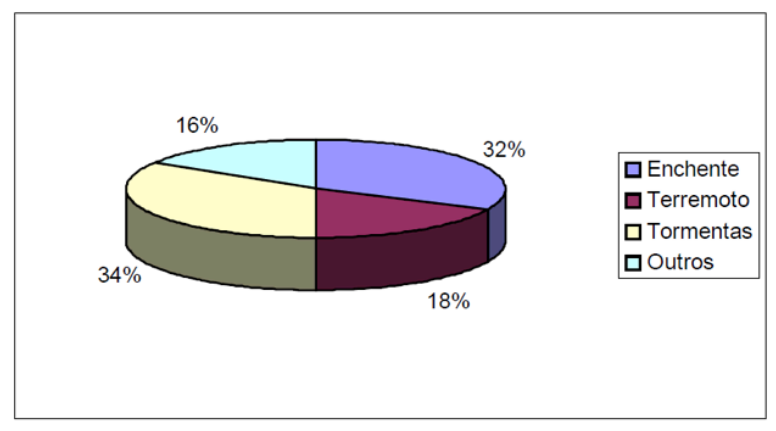

Figura 10: Percentual de Catástrofes Naturais no Mundo (MÜNCHENER RÜCKVERSICHERUNGS-GESELLSCHAFT, 1997 apud RIGHETTO, 2005, p. 16)

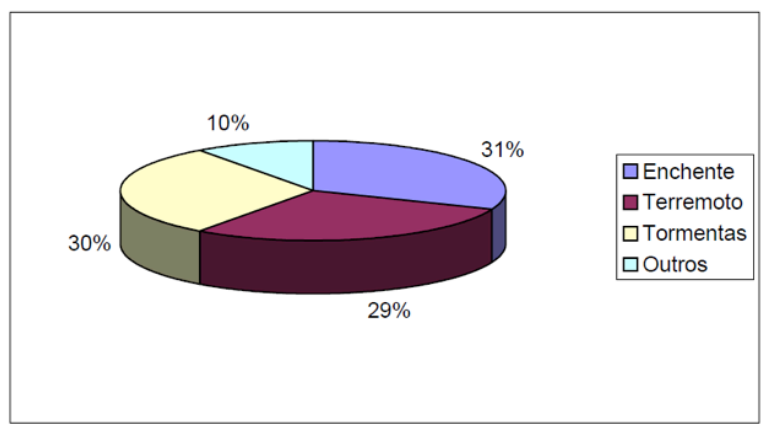

Figura 11: Perdas Financeiras com desastres (MÜNCHENER RÜCKVERSICHERUNGS-GESELLSCHAFT, 1997 apud RIGHETTO, 2005, p. 16)

De acordo com Righetto et al (2003), na Sub-bacia do Córrego do Gregório, as inundações ocorrem rapidamente, de 15 a 30 minutos, atingindo de $50 \mathrm{~cm}$ a $150 \mathrm{~cm}$ no interior das lojas. As inundações mais frequentes afetam mais de 300 estabelecimentos comerciais da região, com perdas estimadas em até $\mathrm{R} \$ 550.000$ por inundação, e atingem uma área potencial inundável de 5 hectares aproximadamente (FINEP / FIPAI / EESC-USP / DAEE-SP, 2003).

Já em relação aos bens imateriais, que como mencionado são aqueles relacionados aos saberes, às habilidades, que não têm consistência material, podemos notá-los quando analisamos as entrevistas realizadas.

A maioria dos entrevistados, tanto lojistas quanto comerciantes populares, trabalham no local há muitos anos, chegando até a 25 anos, e alguns deles já tiveram prejuízos materiais ocasionados pelas inundações, como podemos observar pelos relatos a seguir:

\section{Entrevistador: "Que tipo de prejuízo as inundações já trouxeram para o senhor?"}

\begin{abstract}
"Pra mim, mais de 1.000 reais só essa última vez... Essa chuva não foi só aqui que deu, nas loja também! Até carro rodou. Se você ver o tanto que foi até que a gente perdeu pouco." Jorge, comerciante popular.
\end{abstract}

\begin{abstract}
"Prejuízo de bastante mercadoria, geladeira, computadores. Nessa última enchente, né." Bianca, funcionária de loja do ramo de calçados.
\end{abstract}

"Dois funcionários meus tiveram as motos levadas pela enxurrada..." Cristine, gerente de loja de móveis e eletrodomésticos.

\footnotetext{
".... gente tem o prejuízo de que a loja fecha, não pode trabalhar, a gente perde cliente, entendeu? E se, por
} 
exemplo, dá de manhã, a gente não pode abrir a loja depois do meio dia com a loja toda suja; a loja tem que estar em ordem pra gente abrir. Perder produto, não, mas... ela fica fechada." Rita, funcionária de loja do ramo de cosméticos.

"Já perdi mercadoria. Dessa vez não porque tava tudo no alto" (referente à forte chuva do dia 22 de outubro de 2013) Cíntia, comerciante popular.

Também nos foi narrada a ocorrência de perda de automóveis e motos estacionados próximos à região, contabilizando as perdas materiais não só dos comerciantes quanto aos seus produtos mas também de seus veículos e os de outras pessoas que lá circulavam.

E muitos prejuízos imateriais foram percebidos durante a narrativa dos entrevistados, quando a questão foi:

\section{"Quando começa a chover, isso o remete a alguma experiência ruim sua ou não? Algum medo de perder suas mercadorias?".}

"...depende muito da chuva; é tipo aquelas doenças que você tem que saber como controlar... Não é uma coisa pra perder a cabeça. Muita gente perde porque marcou, entendeu?" Rodrigo, comerciante de banca de jornais e revistas.

"...foi horrível, não tem nem como descrever. Era gente chorando, gente gritando, foi muito feio" (referente à forte chuva do dia 22 de outubro de 2013). Cristine, gerente de loja de móveis e eletrodomésticos.

"O prejuízo não é só financeiro, é meu trabalho também... Então você tá lá na sua casa, e tá vendo essa chuva forte, você já tem que ficar de aviso e vim pro seu comércio, e na maioria das vezes que você se preocupa lá e vem pra cá, e na maioria das vezes, aconteceu o fato. Isso aí é normal, o emocional é sempre assim." Toninho, lojista do ramo de calçados.

"Começa a chover já fico apreensiva, pelos outros também." Cíntia, comerciante popular.

Apesar dos bens perdidos e das situações difíceis relatadas, os comerciantes da região entrevistados nunca cogitaram deixar o local. Como podemos observar no depoimento de Jorge e Toninho:

"Não, não porque não tem outro lugar também, né. Se nós sair daqui pra onde que nós vai? É o lugar que nós temos pra trabalhar." Jorge, comerciante popular.
"E ai saímos os comerciantes dessa área e vai fazer uma piscina aquática?" Toninho, lojista do ramo de calçados.

\section{Entrevistador: "Apesar de tudo ainda compensa ficar aqui?"}

\begin{abstract}
"Mas não tenha dúvida que compensa, com toda esse problema que você tem os prejuízos, você tem que permanecer. Você sai e outro entra, aí o prejuízo continua pro outro....Não tem como pensar em sair de uma área comercial como essa daqui; isso aqui é a área principal da cidade, do comércio. Não pode se pensar assim, acho que é um pessimismo pensar em sair da área comercial." Toninho, lojista do ramo de calçados.
\end{abstract}

\section{Entrevistador: "Já pensou em sair?"}

"Não, a gente ama aqui." Flor, comerciante popular.

A noção de lugar, como pertencimento e identidade, permite perceber que os comerciantes consideram o centro o seu lugar e, por conta disso, desejam continuar ali a despeito do problema com as inundações. Em meio à continuidade das inundações e à permanência dos comerciantes na região, várias maneiras foram criadas por eles para se adaptarem à cheia das águas. Foi possível constatar algumas:

\begin{abstract}
"Em períodos de chuva nós já temos o costume de manter as coisas um pouco mais alta pra prevenir de acontecer alguma coisa. Mas a estrutura que eu tenho aqui já foi feita voltada pra prevenir danos mesmo. Então eu uso o que tenho aqui que já é bem estruturado pra evitar danos ou sujeira." Cássio, comerciante popular.
\end{abstract}

"Vai enchendo você vai erguendo, vai enchendo você vai erguendo. É o que todo mundo faz aqui." Rodrigo, comerciante de banca de jornais e revistas.

"Se nós tiver aqui, nós levantamos as coisas. E se nós não estivermos? Aí perde..." Jorge, comerciante popular.

"É, a gente vê que vai chover, a gente já fecha tudo." Rita, funcionária de loja do ramo de cosméticos.

\begin{abstract}
"Já foi providenciado aumentar a altura do piso, as proteções nas portas. Tudo ajuda, mas nada resolve. Então sempre que tem enchente você tem o prejuízo, mas você tem que tomar suas precauções se não o prejuízo é cada vez maior." Toninho, lojista do ramo de calçados.
\end{abstract}

As dificuldades dos comerciantes em lidar com as enchentes estão, justamente, em suas soluções individuais para um problema que necessidade de um enfoque coletivo. 
A tentativa de adaptar soluções como a elevação de pisos, por exemplo, será sempre paliativa. Contudo, é relevador observar a dificuldade do poder público em criar políticas e ações de prevenção e preparação para diminuir as perdas materiais e imateriais dos afetados pelas enchentes.

A percepção dos entrevistados a respeito do aumento da frequência de inundações (2012 e 2013), frente a um período anterior com poucos eventos (2007-2008), revela que muitos acreditam ser da própria intensidade de precipitação; outros têm diferentes opiniões:

"Ah... porque é muitas construções, né, ao redor do rio. Então isso vai acarretando mesmo; tá cada vez pior, devido ao crescimento da cidade mesmo." Sandro, proprietário de floricultura.

"Acredito que seja muito lixo que as pessoas estão jogando no córrego, a gente via muita coisa boiando na água; era até perigo pra quem estava com os pés dentro d'água, e em volta é tudo cheio de cimento, não tem pra onde a água infiltrar, não tem a mata ciliar que tinha que ter, tudo isso provocou isso daí..." Cristine, gerente de loja de móveis e eletrodomésticos.

"Porque isso aí, que eu saiba, a chuva de 1970 já enchia, e não tinha nada aqui, só tinha mato e já chegou a ter enchente, quer dizer, então imagina agora que tá tudo asfaltado... A tendência é piorar, porque a hora que eles começarem a lotear esses terrenos aqui na frente, que todo mundo vai começar a fazer uma casa no terreno inteiro, aí já era." Rodrigo, comerciante de banca de jornais e revistas.

Para finalizar, alguns entrevistados acreditam não haver mais solução para minimizar as ocorrências de enchentes na área; outros sugeriram formas para que isso ocorra:

"Ah, ação é da defesa civil, de orientar as pessoas de quando ver já pedir pra retirar os carros. Se chover, vai chover, aí até passar. Mas o certo é a defesa civil que tem que fechar a avenida São Carlos..." Rodrigo, comerciante de banca de jornais e revistas.

"Teriam que arrumar esse rio aqui, porque o rio, ele tem um buraco, que é pra água sair, e ele é muito pequeno, ele não é grande, então não escoa muito a água, então a água não vai embora rápido, então até ele subir e a água escoar, demora...e os bueiros: tem esse bueiro aqui e só aquele ali, então só esses dois bueiros não dá conta, teria que ter mais." Patrícia, funcionária de loja do ramo de cosméticos.
"Primeira coisa que tem que fazer é na parte do shopping; tem que afundar aquela parte pra poder escoar melhor as águas. Aí é o primordial. E outra coisa, precisaria fazer, nas duas partes do rio, dos dois lados, uma canalização aqui na Rua Conde do Pinhal, e a outra pegando desde lá de cima da cidade, pra escoar bem na frente, ali perto do shopping." Sandro, proprietário de floricultura.

"Olha, eu acho que pra poder minimizar, ou eles teriam que... - aqui como já é tudo cimentado e não tem mais o que fazer - aprofundar ou fazer mais largo os dutos, pra poder ter mais vazão pra água ou aprofundar o riacho um pouco mais pra dar maior vazão pra água. Porque não tem mais o que fazer aqui; vai destruir o centro da cidade? Nós é que estamos no lugar errado; o rio é que está certo. Então já não tem mais o que fazer; acho que é só isso, aprofundar o lago e aumentar os dutos pra vazão da água, eu acredito." Cristine, gerente de loja de móveis e eletrodomésticos.

"Eu acho que o principal é a conscientização da população em termos de como manipular o lixo. Acho que o principal problema de causar inundação é o mau manuseio do lixo que a própria população faz, não só por parte da administração da cidade." Cássio, comerciante popular.

"Pensar em obras contra enchente, não tem dúvida.. Assim como foram feitas obras no passado que foram melhorando gradativamente, tem que continuar fazendo pra melhorar sempre. Porque, se não cuidar, a cidade cresce, vem asfalto e não tem onde a água desaparecer; então ela vem pelo asfalto e cai na baixada." Toninho, lojista do ramo de calçados.

"...eu vejo muito a falta de conscientização do povo, porque hoje você vê grandes quantidades de lixo na beira dos rios, das nascentes, ou na própria via pública você vê uma grande quantidade. Quando o povo tiver uma conscientização do que ele tá causando, evitaria esse tipo de problema também." Marcelo, funcionário de loja do ramo de calçados.

Há uma grande extensão de medidas para redução das enchentes apresentadas pelos comerciantes afetados por esse problema ambiental, desde soluções técnicas, como obras contra inundações, até soluções que envolvem educação ambiental para realizar uma abordagem mais sistêmica.

De acordo com o Diretor de Segurança Pública e Defesa Civil, Pedro Caballero, as ações de prevenção que estão sendo desenvolvidas, em relação às inundações no centro, são: 
"O que está construído neste momento nós não podemos mexer. A única coisa que podemos fazer de forma imediata é criar um sistema de alerta, porque o risco, o perigo está lá, a vulnerabilidade das pessoas que circulam; essa vulnerabilidade é que temos que eliminar. Se eu tenho o conceito que a ONU me diz que risco é perigo vezes, ou mais a vulnerabilidade, se eu eliminar um desses dois eu já elimino o risco (...). Então a minha ideia e da equipe é trabaIhar com sistema de alerta. É preciso ter um bom sistema de hidrometeorologia. Então eu tenho que pegar vários dados; não posso confiar em um só (...) "

O diretor Pedro Caballero comenta que é necessário um trabalho em conjunto de vários órgãos. Cita que a USP tem um equipamento que mede a quantidade de água precipitada por satélite (por meio de um satélite europeu), que muitas vezes é mais eficiente que pluviômetros convencionais, pois seriam necessários, no mínimo, três pluviômetros, um na cabeceira, um no meio e um no final do córrego, segundo o entrevistado.

Com relação às ações de preparação que a Defesa Civil vem desenvolvendo, há um plano de contingência para verão, por meio do qual já foram iniciados plantões de meteorologia e observação. Além disso, eles estão interligados ao sistema de câmeras da polícia civil. Assim, dependendo do nível de precipitação, são acionados agentes municipais de trânsito, a guarda municipal e os bombeiros para atuarem nas áreas afetadas.

Como resposta às inundações do Córrego do Gregório na região do Mercado Municipal, Caballero explicou que o primeiro passo é saber os locais específicos que estão sendo atingidos para então começarem os trabalhos. Ele ainda ressaltou que o problema só é realmente considerado quando as pessoas dão visibilidade ao fato, sugerindo que se ninguém o vê, ele não existe.

\section{Entrevistador: "Por que o senhor acha que as inunda- ções voltaram?"}

"Olha, vou te dizer uma coisa, o que não se tinha era chuva de dia; você tinha chuvas à noite. Então, chuva à noite no Mercado ninguém vê; se é de madrugada, cinco ou seis pessoas veem; se a imprensa não for chamada, ninguém vê."

Novamente as chuvas aparecem como o elemento causador do desastre. Contudo, uma solução mais sistêmica começa a ser aventada pelo diretor da Defesa Civil municipal ao responder sobre o que ser feito para minimizar essa situação:

"Eu acho que se há uma decisão política, né, que é importante uma decisão política; você tem que ter medidas estruturais e não estruturais, né, se não vai mexer no leito, no centro mesmo; você vai ter todo um sistema hidráulico de macro e micro drenagem, ou seja, desvio de água, retenção de água, tudo isso daí. Por quê? Porque hoje você está jogando assim, né, então ou você desvia pra frente a jusante, né, pois você ainda tem o problema lá do gargalo (referindo-se ao estrangulamento que o córrego sofre quando passa por debaixo do aterro que sustenta a linha férrea) ainda que não está resolvido, ou seja, você tem, é possível, sim; se quiserem, é possível, sim."

Quando o Poder Público foi questionado sobre as inundações na região do Mercado Municipal de São Carlos, Rogério Almeida, arquiteto da Secretaria Municipal de Habitação e Desenvolvimento Urbano, relatou que nenhuma medida está sendo ttomada e que existe, porém, a intenção pessoal de destamponamento do Córrego do Gregório. Fernando Almeida, arquiteto da Secretaria Municipal de Habitação e Desenvolvimento Urbano, salienta que é algo que já vem ocorrendo há algum tempo devido ao tamponamento da praça, que é um reflexo do problema do shopping, a jusante do centro da cidade, local onde existe um aterro que impede a saída da água, e também ao formato da seção pela qual o rio passa, que em certo local se torna mais estreito, provocando um remanso e inundando o Mercado, e ainda completa:

\footnotetext{
"Quanto às medidas que estão sendo feitas, sempre, quando tem essas enchentes, por enquanto, estão sendo tomadas medidas emergenciais, as obras contra inundação. O problema é conseguir recurso; então resolvemos pontualmente o problema." Fernando Couto Rosa Almeida, arquiteto da Secretaria Municipal de Habitação e Desenvolvimento Urbano de São Carlos.
}

Com relação à área próxima ao shopping, ele nos contou que existem estudo, projeto aprovado e verba destinada à obra que abrirá o aterro existente resolvendo a problemática da região do Mercado, apenas restando "acertar umas pontas" para que se inicie. Porém o projeto voltado à seção do córrego ainda é inexistente.

Com relação à periodicidade das inundações e do suposto período de ausência de inundações de grande porte na região, Fernando nos diz que praticamente todo ano tem ocorrido e que isso varia de acordo com a intensidade de chuva e do período de retorno. Rogério comentou que a causa do retorno desse tipo de inundações é a retirada de cobertura vegetal, a construção de novas ruas, impermeabilizando o solo e a quantidade de lixo presente dentro do córrego.

Quando questionados se é possível acabar com as inundações da região em questão, ambos responderam de forma positiva, como exemplificado pela fala de Fernando: 
"Sim, sim, a abertura do canal na frente (referente à área próxima ao shopping) é uma solução." Fernando Couto Rosa Almeida, arquiteto da Secretaria Municipal de Habitação e Desenvolvimento Urbano de São Carlos.

\section{CONCLUSÃO}

As inundações ocorrem desde os primeiros relatos de 1905 até os dias de hoje e provocam danos materiais e imateriais; apesar de sua longevidade histórica e das obras hídricas realizadas para "acabar com problema", há uma persistência do fenômeno. Na sociedade de risco, as ameaças operam de forma silenciosa e estão ligadas à própria forma como a sociedade atual busca desenvolver seu bem-estar e seu progresso.

Os usos dentro da bacia do Córrego do Gregório é que geram as ameaças que deixam uma parte da população vulnerável aos desastres. Vários pontos são citados em comum acerca das possíveis causas das enchentes, como: (1) o encontro do córrego do Gregório com seu afluente Simeão (que é totalmente tamponado) na região Central, unindo águas de duas microbacias na região crítica; (2) o estrangulamento que o córrego sofre no aterro que sustenta a linha férrea, que não é grande o suficiente para a passagem de todo volume de água que chega em eventos de chuva intensas; (3) a mudança da seção interna do córrego, pois também houve um estrangulamento; (4) o lixo depositado pelas próprias pessoas que trafegam na região, que prejudica o fluxo da água; e (5) O próprio volume de chuva, considerado 'alto' nas vezes de ocorrência de inundações.

Porém, ao conjunto de soluções técnicas citado acima, há a necessidade de ir além. Isso significa a busca de soluções mais sistêmicas e com um alcance maior, tendo em vista que as inundações estão relacionadas com a macro e a micro drenagem de toda bacia do Córrego do Gregório e com a utilização do ecossistema próximo. A inobservância do conjunto de relações existentes no evento das inundações é o que fortalece a insistência em soluções pontuais ou individuais que, ao não serem tratadas holisticamente, estão fadadas ao fracasso ao dispender recursos em obras onerosas que minimizam, mas não resolvem o problema. Nesse sentido, é preciso, também, modificar e fortalecer a relação da população com o Córrego do Gregório, por meio de programas de educação ambiental que permitam uma mudança voluntária de comportamento em relação a como o citado córrego é tratado.

\section{REFERÊNCIAS}

DE BIASI, M. A carta clinográfica: os métodos de representação e sua confecção. Revista do Departamento de Geografia. São Paulo: Faculdade De Filosofia, Letras e Ciências Humanas - USP, n. 6, 1992. p. 45-60.

BORGES, J.Q.A. O impacto da ocupação de fundos de vale em áreas urbanas. Caso: Córrego do Gregório São Carlos (SP). São Carlos/SP: Dissertação (Mestrado) - Programa de Pós-Graduação em Engenharia Urbana. Universidade Federal de São Carlos, 2006.

BRASIL. Decreto N 7.257, de 4 de agosto de 2010. Regulamenta a Medida Provisória no 494, de 2 de julho de 2010, para dispor sobre o Sistema Nacional de Defesa Civil - SINDEC, sobre o reconhecimento de situação de emergência e estado de calamidade pública, sobre as transferências de recursos para ações de socorro, assistência às vítimas, restabelecimento de serviços essenciais e reconstrução nas áreas atingidas por desastre, e dá outras providências.

\section{DEFESA CIVIL DE SÃO BERNARDO DO CAMPO.}

Enchente, Inundação, Alagamento ou Enxurrada? 2013. Disponível em < http://dcsbcsp.blogspot.com.br/2011/06/ enchente-inundacao-ou-alagamento.html> Acesso em 31 de out de 2013.

FINEP-CT-HIDRO/FIPAI-EESC-USP/DAEE-SP. Experimento piloto de gerenciamento integrado de bacias urbanas para o Plano Diretor de São Carlos, SP. São Carlos: 2003. Conv. 01.02.0086.00 (www.busplanodiretor.hpg.com.br)

FIPAI / PMSC. Fundação para o Incremento da Pesquisa e Aperfeiçoamento Industrial / Prefeitura Municipal de São Carlos. Implantação do Projeto de Renaturalização de Áreas de Fundo de Vale visando o Plano Diretor de Bacias Hidrográficas Urbanas Degradadas, Protijuco - Projeto de Recuperação Ambiental das Várzeas, visando ao Plano Diretor a montante da Bacia do Tijuco Preto, contrato administrativo $N^{\circ}$ 019/2003. São Carlos, 2003, 12p. $1^{\circ}$ Relatório.

GILBERT, C. Studying disaster: changes in the main conceptual tools. In: QUARANTELLI, E.L. What is a disaster? Perspectives on the question. Routledge: London and New York, 1998. p.11- 18. 
GONÇALVES, J. C. A especulação imobiliária na formação de loteamentos urbanos. Rio de Janeiro: e-papers, 2010.

BRASIL. Ministério de Ciência e Tecnologia/ Centro de Estudos e Gestão Estratégica. Diretrizes estratégicas para o fundo de recursos hídricos de Desenvolvimento Científico e Tecnológico. Brasília - DF, 2001.

MENDES, H.C.; MENDIONDO, E.M. Histórico da Expansão Urbana e Incidência de Inundações: O Caso da Bacia do Gregório, São Carlos - SP. Revista Brasileira de Recursos Hídricos - RBRH. Volume 12. n.1 Jan/Mar, p.17-27, 2007.

MMA, et al. Definição da planície de inundação da cidade de Governador Valadares. Brasília-DF, 2004.

PORTAL BRASIL. Material e imaterial. Disponível em < http://www.brasil.gov.br/cultura/2009/10/material-e-imaterialHYPERLINK "http://www.brasil.gov.br/cultura/2009/10/material-e-imaterial\%3E " >Acesso em 31 de Out de 2013.

PREFEITURA MUNICIPAL DE SÃO CARLOS. Defesa Civil. (s/d) Disponível em: <http://www.saocarlos.sp.gov.br/ index.php/prefeitura/utilidade-publica/defesa-civil.html\#COMO\%20SURGIU>. Acesso 06 Nov de 2013.

PREFEITURA MUNICIPAL DE SÃO CARLOS. História de São Carlos. (s/d) Disponível em: <http://www.saocarlos.sp.gov.br/index.php/historia-da-cidade/115269-historia-de-sao-carlos.html>. Acesso 06 Nov de 2013.

RIGHETTO, J. M. Modelo de Seguro para Riscos Hidrológicos no Contexto de Manejo Integrado de Bacias Hidrográficas. São Carlos/SP: Dissertação (Mestrado) Programa de Pós-Graduação em Ciências da Engenharia Ambiental. Escola de Engenharia de São Carlos, Universidade de São Paulo, 2005.

RIGHETTO, J. M., MENDIONDO, E. M.. Avaliação de riscos hidrológicos: principais danos, causas e propostas de seguro contra enchentes In: III Simp. Rec. Hídricos do Centro-Oeste, Goiânia (GO), Anais, ABRH-Acquacon, 2004.

SALVADOR, A. et al. Bacia hidrográfica do gregório. Disponível em <http://www.cdcc.usp.br/bio/greginicial. htm> Acesso em 6 de Nov de 2013

TUCCl, C. E. M. Águas urbanas. Estudos avançados. São Paulo: Edusp, 2008.
VALENCIO, N. F. L. S. Da morte da quimera à procura de Pégaso: a importância da interpretação sociológica na análise do fenômeno denominado desastre in: VALENCIO, N. F.L. S.; SIENA, M.; MARCHEZINI, V.; GONÇALVES, J. C. (org.). Sociologia dos desastres: construção, interfaces e perspectivas no Brasil. VOLUME I. São Carlos: RiMA editora, 2009. 